\title{
Transdermal Buprenorphine for Acute Pain in the Clinical Setting: A Narrative Review
}

This article was published in the following Dove Press journal:

Journal of Pain Research

\author{
Joseph V Pergolizzi Jr (D) \\ Peter Magnusson ${ }^{2,3}$ \\ Jo Ann LeQuang' \\ Frank Breve \\ Kailyn Mitchell' \\ Maninder Chopra $\mathbb{D}^{5}$ \\ Giustino Varrassi (iD) \\ 'NEMA Research, Inc., Naples, FL, USA; \\ ${ }^{2}$ Centre for Research and Development, \\ Region Gävleborg/Uppsala University, \\ Gävle, Sweden; ${ }^{3}$ Department of \\ Medicine, Cardiology Research Unit, \\ Karolinska Institutet, Stockholm, Sweden; \\ ${ }^{4}$ Department of Pharmacy Practice, \\ Temple University School of Pharmacy, \\ Philadelphia, PA, USA; ${ }^{5}$ Decision \\ Alternatives, LLC, Frederick, MD, USA; \\ ${ }^{6}$ Paolo Procacci Foundation, Rome, Italy
}

\begin{abstract}
Transdermal buprenorphine is indicated for chronic pain management, but as its role in the clinical management of acute pain is less clear, this narrative review examines studies of the patch for acute pain, mainly in the postoperative setting. Although perhaps better known for its role in opioid rehabilitation programs, buprenorphine is also an effective analgesic that is a Schedule III controlled substance. Although buprenorphine is a partial agonist at the $\mu$-opioid receptor, it is erroneous to think of the agent as a partial analgesic; it has full analgesic efficacy and unique attributes among opioids, such as a ceiling for respiratory depression and low "drug likeability" among those who take opioids for recreational purposes. Transdermal buprenorphine has been most thoroughly studied for acute pain control in postoperative patients. Postoperative pain follows a distinct and predictable trajectory depending on the type of surgery and patient characteristics. Overall, when the patch is applied prior to surgery and left in place for the prescribed seven days, it was associated with reduced postoperative pain, lower consumption of other analgesics, and patient satisfaction. Transdermal buprenorphine has been evaluated in clinical studies of patients undergoing gynecological surgery, hip fracture surgery, knee or hip arthroscopy/ arthroplasty, shoulder surgery, and spinal surgery. Transdermal buprenorphine may also be appropriate pain medication for controlling pain during postsurgical orthopedic rehabilitation programs. Transdermal buprenorphine may result in typical opioid-associated side effects but with less frequency than other opioids. Despite clinical reservations about transdermal buprenorphine and its potential role in acute pain management in the clinical setting, clinical acceptance may be hampered by the fact that it is off-label and buprenorphine is better known as an opioid maintenance agent rather than an analgesic.
\end{abstract}

Keywords: acute pain control, ceiling effect of buprenorphine, geriatric pain patients, gynecological surgery, hip arthroscopy, knee arthroscopy, opioid-associated side effects, orthopedic rehabilitation, orthopedic surgery, postoperative pain, spinal surgery, transdermal buprenorphine dosing

\section{Plain Language Summary}

Transdermal buprenorphine is a patch that adheres to the skin and delivers a slow-release of the pain reliever over a period of several $\mu$ days. The buprenorphine patch is indicated for chronic pain, that is, pain that lasts for a long time and is not very responsive to treatment. It is not known whether the buprenorphine patch would work well for shorter-duration pain, such as pain following surgery or the pain associated with acute conditions such as pancreatitis. Buprenorphine is an opioid and a Schedule III controlled substance which means it is considered less dangerous than Schedule II substances, such as morphine or oxycodone. Several small studies have explored the use of the buprenorphine patch to treat acute pain and found it to be effective and safe. Like all opioids, buprenorphine may result in opioid-associated side effects.
Correspondence: Jo Ann LeQuang NEMA Research, Inc., 4005 Technology Drive, Suite 1008-V, Angleton, TX, 77515, USA

Tel + I-979-824-025I

Email joannlequang@gmail.com 
When the patch is applied before surgery and left in place for several days after surgery, it helps to control pain. It is also not necessary for the patient to take oral medications every few hours or to receive injections for pain. While the transdermal buprenorphine system appears to hold promise as an analgesic for managing short-term painful conditions in the hospital or clinical setting, there may be barriers to its use. For one thing, it is not yet approved by the Food and Drug Administration for short-term pain control. Second, many physicians associate buprenorphine as a drug used for opioid rehabilitation (like methadone) and do not consider it as a pain reliever. Finally, not all prescribers are familiar with the use of pain-relieving transdermal patches and may hesitate to recommend them.

\section{Introduction}

The role of transdermal buprenorphine for the control of chronic cancer and noncancer pain ${ }^{1,2}$ has been established, but its role for acute pain management is less clear. Buprenorphine is strongly associated with opioid maintenance therapy to the point that clinicians may not be aware that transdermal buprenorphine is available and indicated for chronic pain. The extension of buprenorphine transdermal patches from chronic to acute pain care seems to be reasonable, in that other opioids such as oxycodone or morphine are used in both acute and chronic pain cases. The purpose of this narrative review is to evaluate the current literature for evidence of the use of transdermal buprenorphine for acute pain along with offering e clinical guidance about its dosing and related safety concerns.

Acute pain has been defined as the awareness of noxious signaling from recently damaged tissues and can be complicated by peripheral sensitization and sensitization within the central nervous system. ${ }^{3}$ The intensity of acute pain can vary with the inflammatory processes, the degree of healing of the tissue, movement, and other factors. Clinicians often use temporal definitions for acute, subacute, and chronic pain with acute pain being pain that lasts under four weeks; chronic pain is pain that persists for 12 weeks or more despite analgesia. Subacute pain is defined as pain that has lasted at least four weeks but has not yet lasted 12 weeks. $^{3}$

\section{Methods}

The authors searched the database of PubMed, without delimiters, for the keyword "transdermal buprenorphine acute pain," which yielded 27 results. They also searched "buprenorphine acute pain" with no delimiters and retrieved 262 results. There was considerable overlap in the searches with all items in the first search appearing in the second. The search was conducted in December 2020. In the same time frame, we searched this same key word with no delimiters in Google Scholar. Many of these articles addressed the topic of managing acute pain in patients on buprenorphine for opioid maintenance therapy and as such were not utilized in this review. We included all types of articles (reviews, case reports, commentaries, trials), and excluded studies that were not specifically about the transdermal formulation of buprenorphine or studies involving experimental pain.

\section{Results}

This narrative review describes briefly the pharmacology of buprenorphine and then the use of transdermal buprenorphine in clinical settings for the treatment of acute pain. Note that this is an off-label indication.

\section{Buprenorphine Pharmacology}

Buprenorphine is an atypical opioid derived from the opium alkaloid thebaine from the poppy plant, Papaver somniferum. ${ }^{4}$ It has an affinity for the $\mu, \delta$, and $\mathrm{K}$ opioid receptors as well as for the opioid receptor-like-1 (ORL1). ${ }^{5}$ Since buprenorphine is a partial agonist at the $\mu$ opioid receptor, it is sometimes erroneously described as possessing only partial analgesic efficacy; actually, buprenorphine has full analgesic efficacy and its unique structure may contribute to the fact that it confers a lower risk for respiratory depression and milder side effects. ${ }^{4,6-8}$ Its role in the the treatment of certain types of chronic cancer and noncancer pain syndromes in appropriate patients has been established. $^{9-12}$

Although an opioid product, buprenorphine is a Schedule III, rather than Schedule II, controlled substance by the Drug Enforcement Administration. ${ }^{13}$ This lesser scheduling compared to oxycodone or morphine may be due to several characteristics of the drug. Buprenorphine has a ceiling effect for respiratory depression, meaning that the risk for opioid-induced respiratory depression does not increase beyond a certain dose. ${ }^{14}$ However, it has no such ceiling effect for analgesic benefit. ${ }^{15}$ In studies of "drug likeability" among people who seek opioids for their psychoactive effects, buprenorphine is not viewed as an attractive or interesting drug. ${ }^{16}$ Since buprenorphine has hepatic metabolization, it is safe for patients with renal dysfunction. ${ }^{15}$ This means buprenorphine can be administered to elderly patients and those with renal dysfunction without the need to adjust the dose. $^{16}$ 
Transdermal buprenorphine is indicated for pain rather than opioid maintenance therapy. Buprenorphine's characteristics of low molecular weight, high lipophilicity, high affinity for the $\mu$-opioid receptor, and low bioavailability make it well suited for transdermal, parenteral, or buccal administration compared to oral administration. ${ }^{17}$ The transdermal system offers other advantages to patients in that it is convenient for patient and prescriber, is not associated with any pill burden, and requires no patient attention to remember each dose.

\section{Analgesia for Acute Painful Conditions Acute Pancreatitis}

There were no studies of transdermal buprenorphine for use in patients with acute pancreatitis, but the literature discusses the role of buprenorphine in this population. Opioids are often used in the treatment of acute pancreatitis, although it is unclear if this is the most effective and safest treatment. In a systematic review (five studies, $\mathrm{n}=277$ ), various opioids such as transdermal fentanyl, subcutaneous morphine, and intravenous and intramuscular buprenorphine were all found to reduce pain intensity in acute pancreatitis patients and could be described as effective analgesics without incremental risk over other analgesic choices. $^{18}$ Intravenous buprenorphine was more effective than intravenous procaine in a study of 40 patients with acute pancreatitis or an acute bout of chronic pancreatitis. ${ }^{19}$ This suggests that transdermal buprenorphine might be a suitable and effective analgesic product for patients with acute pancreatitis, although no clinical studies were found using this product for acute pancreatitis pain.

\section{Postoperative Acute Pain}

Nearly all studies about transdermal buprenorphine assessed it within the setting of postoperative pain. Postoperative pain has a distinct trajectory, being most intense immediately following surgery and then diminishing in a relative predictable pattern, based on type of surgery, over the course of the next days. In many cases, postoperative pain is treated with a combination product of opioid and nonopioid. Analgesic strategies for postsurgical pain either involve short-term treatment (over one to several days) or a longer period of treatment (several weeks) with decrementing doses. The transdermal buprenorphine patch poses a different paradigm for postoperative pain in that it sets and maintains a consistent dose over multiple days, usually sufficient for tissue healing and resolution of painful symptoms. A seven-day patch maps onto many postsurgical pain trajectories. Its constant dosing may eliminate episodes of breakthrough pain associated with analgesic gaps between doses. ${ }^{20}$

A systematic review and meta-analysis (nine studies, $\mathrm{n}=615$ ) found that the transdermal buprenorphine patch was usually applied six to 48 hours prior to surgery and then maintained for one to eight days after surgery. The incidence of side effects varied among studies, but most studies showed that transdermal buprenorphine reduced postoperative pain, was associated with less postoperative consumption of oral analgesics, and resulted in higher patient satisfaction than placebo or comparator (tramadol, celecoxib, flurbiprofen, acetaminophen). ${ }^{21}$

Gynecological Surgery In a study of 45 women undergoing open gynecological surgery, patients were randomized to receive different doses of the transdermal buprenorphine patch $(17.5 \mu \mathrm{g} / \mathrm{h}, 35 \mu \mathrm{g} / \mathrm{h}$ or $52.5 \mu \mathrm{g} / \mathrm{h})$ with rescue morphine and intravenous ketorolac available. ${ }^{22}$ An inverse association was found between the transdermal patch dose and the use of morphine $(\mathrm{p}=0.04)$, ketorolac $(p=0.04)$ or both $(p=0.02)$. No serious adverse events were reported and the rate of nausea and vomiting was similar among all three groups. Patients with fewer doses of rescue medication reported higher satisfaction. Thus, the effectiveness of the buprenorphine patch was directly correlated to the dose although all groups consumed some rescue analgesics in the initial hour after surgery. The higher doses of buprenorphine in this study were correlated to greater pain control, less consumption of rescue medication, but not higher incidence of side effects. ${ }^{22}$

In a placebo-controlled trial, abdominal hysterectomy patients were randomized to groups with transdermal buprenorphine patches at doses of 10,15 , and $20 \mu \mathrm{g} / \mathrm{h}$ and pain intensity was measured at 30,60, 90 minutes after surgery and 2, 4, 8, 12, 16, 20, and 24 hours. ${ }^{23}$ Pain levels were assessed at rest and with movement. Mean pain scores were lower for all transdermal buprenorphine groups than placebo groups and related to dose. The mean score of pain with movement was $2.07 \pm 1.08,2.0 \pm 1.00$ and $1.87 \pm 1.02$ for 10,15 , and $20 \mu \mathrm{g} / \mathrm{h}$, respectively; the mean pain score in the placebo group was $3.3 \pm 1.98$. Pain scores at rest were $1.0 \pm 0$ for all transdermal buprenorphine groups regardless of dose and $2.8 \pm 1.02$ for placebo patients. Adverse events overall among transdermal buprenorphine patients were $53.6 \%, 67.7 \%$, and $82.8 \%$ for 10 , 15 , and $20 \mu \mathrm{g} / \mathrm{h}$ with nausea, drowsiness the most 
frequently reported adverse event. No adverse events were reported in the placebo patients. ${ }^{23}$

\section{Orthopedic Surgery}

Hip Trauma. In a study of 50 adult orthopedic patients undergoing surgery for hip fracture, one group was administered a transdermal buprenorphine patch $10 \mu \mathrm{g} / \mathrm{h}$ the day prior to surgery while the other group received $50 \mathrm{mg}$ oral tramadol three times daily after surgery. ${ }^{17}$ Rescue analgesia was available in the form of oral diclofenac or acetaminophen. At each of the seven days following surgery, pain intensity scores at rest or upon movement were significantly lower in the transdermal buprenorphine group, which also had significantly lower consumption of rescue medications $(68 \%$ of transdermal buprenorphine patients needed rescue analgesia versus $100 \%$ of the tramadol patients). Transdermal buprenorphine patients had lower rates of vomiting and reported significantly higher patient satisfaction. ${ }^{17}$

Knee or Hip Arthroscopy/Arthroplasty. Following total knee arthroscopy, 160 patients were randomized to receive the $10 \mu \mathrm{g} / \mathrm{h}$ transdermal buprenorphine system or oral celecoxib with morphine also provided. In the first 72 hours after surgery, there was significantly lower morphine consumption in the buprenorphine patch group than the celecoxib group. Transdermal buprenorphine patients also had lower pain scores during rest and activity. No remarkable adverse events occurred in either group. ${ }^{24}$

In a study of 50 adults undergoing total hip or knee arthroplasty, the transdermal buprenorphine patch $10 \mu \mathrm{g} / \mathrm{h}$ was applied 12 hours before surgery and patients had access to intravenous acetaminophen (no opioids) as rescue medication. ${ }^{25}$ Twenty percent of patients required rescue analgesia at four hours, $32 \%$ at eight hours, and $16 \%$ at 12 hours. No patient required supplemental analgesia in the first two hours after surgery. A total of 544 observations were carried out on 50 patients during the first 72 hours after surgery to evaluate nausea and/or vomiting; 6 of the 544 observations were positive for nausea and/or vomiting. No patient complained of pruritus. $^{25}$

Shoulder Surgery. In an observational study of 20 patients undergoing shoulder surgery, all were treated with transdermal buprenorphine $35 \mu \mathrm{g} / \mathrm{h}$ applied 24 hours before surgery. ${ }^{26}$ Intramuscular ketorolac $30 \mathrm{mg}$ was available as rescue medication. One quarter $(25 \%)$ of patients required rescue medication in the first 24 hours after surgery. At 48 hours following the operation, a visual analog pain intensity scale of 1 was recorded for all patients $(100 \%){ }^{26}$

Spinal Surgery. In a randomized, double-blind, prospective study $(n=70)$ of adult elective spinal surgery patients, patients were randomized to receive a transdermal buprenorphine patch $10 \mu \mathrm{g} / \mathrm{h}$ or a sham patch, applied 24 hours before surgery. ${ }^{20}$ In the transdermal buprenorphine group, $14 \%$ required no rescue medication compared to $100 \%$ of the sham patch group, which also consumed significantly more tramadol $(\mathrm{p}<0.001)$. At all of the study time points, pain intensity as measured on a visual analog scale was significantly lower in the transdermal buprenorphine group $(p<0.001)$. There were no reports of nausea in the transdermal buprenorphine group, but three patients in the placebo group experienced nausea. ${ }^{20}$

In a prospective, randomized, controlled noninferiority trial, transdermal buprenorphine at several doses $(5,7.5,10,15$, and $20 \mu \mathrm{g} / \mathrm{h})$ was compared to oral tramadol $(150,200,250$, and $300 \mathrm{mg}$ ) for postoperative pain management after single-level spinal fusion surgery. At seven days, transdermal buprenorphine was not inferior to tramadol and at two-weeks pain evaluations for both groups were similar. Adverse events were similar for both agents. ${ }^{27}$

\section{Postoperative Pain Control in the Elderly}

A study of 20 elderly patients (mean age 78 ) undergoing orthopedic surgery evaluated buprenorphine transdermal systems as postsurgical analgesia. ${ }^{28}$ Patients received a patch with a $35 \mu \mathrm{g} / \mathrm{h}$ dose one day before surgery and following surgery, all patients showed an average visual analog scale score of pain intensity of 3.7 at 12 hours, 2.5 at 24 hours, and 1.0 at 48 hours. Two of the 20 patients experienced postoperative nausea and vomiting and there was one case of application site irritation. The study concluded that transdermal buprenorphine was an effective way to control pain following orthopedic surgery in older patients and obtained high satisfaction scores from patients. $^{28}$

In a study of 200 total knee arthroplasty patients between the ages of 60 and 75 years, patients were randomized to receive transdermal buprenorphine $5 \mu \mathrm{g} / \mathrm{h}$ or a combination of oral acetaminophen and tramadol at the end of the procedure with intravenous diclofenac available as a rescue medication. ${ }^{29}$ The transdermal buprenorphine group had significantly lower pain intensity scores for pain on movement and used less rescue medication, such that the transdermal patch was deemed to be more effective at 
pain control over seven days and with fewer systemic side effects. $^{29}$

\section{Pain Management During Orthopedic Rehabilitation Programs}

In a study of 315 adults who underwent distal radius fracture repaired with volar locking plate fixation, patients underwent the conventional six-week rehabilitation program following surgery. ${ }^{30}$ Pain medication was administered for the initial two weeks of this rehabilitation and then discontinued. For these first two weeks, the prospective cohort study assigned groups to either $200 \mathrm{mg}$ celecoxib twice a day $(n=149)$, transdermal buprenorphine 5 $\mu \mathrm{g} / \mathrm{h}(\mathrm{n}=89)$, or codeine/ibuprofen $13 / 200 \mathrm{mg}$ twice a day $(n=77)$. Pain was assessed at rest, during daily activities, and during rehabilitation exercises each week along with functional metrics such as flexion and range of motion. Patients who received the transdermal buprenorphine patch or took the combination codeine/ibuprofen medication had greater pain control during rehabilitation, better compliance with the rehabilitation program, and faster functional recovery. ${ }^{30}$

\section{Safety}

Buprenorphine has side effects similar to other opioids, such as dizziness, nausea, constipation, vomiting, pruritus, fatigue, and somnolence but these side effects are not as frequent with buprenorphine as with certain other opioids, such as morphine. ${ }^{8}$ For instance, according to package literature, opioid-induced constipation with opioid products such as morphine or oxycodone occurs at a rate of $8 \%$ to $31 \%$ but the incidence is $13 \%$ for transdermal buprenorphine. ${ }^{9}$ The most serious adverse event of any opioid is potentially life-threatening opioid-induced respiratory depression. While buprenorphine can induce respiratory depression, it has a ceiling effect for this adverse effect meaning that escalating doses above a certain point do not increase the risk of respiratory depression. ${ }^{14,31,32}$ Respiratory depression with other opioids has an incidence ranging from $1 \%$ to $11 \%{ }^{15}$

Of concern with any transdermal system are cutaneous effects. In a study of five chronic pain patients using a transdermal buprenorphine patch and suffering from contact dermatitis were evaluated with patch tests and placebo and it was found that all five patients were reacting to the principal ingredient. A cohort of 28 healthy controls tested negative $(100 \%)$. The investigators described this as delayed hypersensitivity to transdermal buprenorphine. ${ }^{33}$

Cardiovascular adverse events have not been reported with buprenorphine, although it may prolong the QT interval in a dose-dependent fashion. In a pair of randomized, placebo- and positive-controlled parallel-group, doseescalating clinical studies, buprenorphine transdermal patches at the therapeutic dose of $10 \mu \mathrm{g} / \mathrm{h}$ were not associated with QT interval prolongations over 13 days of use. However, at supratherapeutic doses of 40 and $80 \mu \mathrm{g} / \mathrm{h}, \mathrm{QT}$ prolongation occurred to a similar extent as with moxifloxacin $400 \mu \mathrm{g} .{ }^{34}$ Despite these findings, those authors and others have not found any association between transdermal buprenorphine and pro-arrhythmic effects. ${ }^{34,35}$

Long-term use of buprenorphine will result in dependency on the drug; that is the normal and expected result of chronic use of any opioid. A once-only use of a sevenday patch treatment of buprenorphine should not result in dependence or tolerance. Longer-term use may result in tolerance (requiring escalating doses) or dependence (meaning the drug must be tapered slowly rather than discontinued abruptly). ${ }^{36}$

Buprenorphine is not well "liked" by people who seek the psychoactive effects of opioids and the transdermal delivery system is thought to further deter abuse because it is impossible to extract the active agent efficiently from the patch. In a RADARS System study conducted 2011 to 2013, transdermal buprenorphine was diverted and abused at low rates compared to other opioids. Even when adjusted for prescriptions dispensed, these rates remained low for transdermal buprenorphine suggesting that even with greater access and availability, the patch was not subject to as much diversion or inappropriate use as oral opioid analgesics and other forms of buprenorphine. ${ }^{37}$

\section{Dosing}

The transdermal buprenorphine patch is available in 5, 10, and $20 \mu \mathrm{g} / \mathrm{h}$ doses and other doses can be achieved by cutting the patch or using two patches (for example, $15 \mu \mathrm{g}$ / $\mathrm{h}$ could utilize one 5 and one $10 \mu \mathrm{g} /$ patch concurrently). An opioid-naïve patient administered a patch for shortterm management of acute pain should be started at the lowest effective dose, likely $5 \mu \mathrm{g} / \mathrm{h}$, and patients should be monitored during the first 24 hours. ${ }^{36}$

If the transdermal buprenorphine patch is to be discontinued after seven days with the plan of switching the patient to an oral opioid or some other pain reliever, it is recommended that the buprenorphine patch be removed 
and 24 hours elapse before the new medication is started. ${ }^{36}$ If the patient's acute pain therapy concludes with the use of one patch, it can be removed after seven days and no withdrawal or other adverse effects should be anticipated. If the patch is removed but the patient still experiences pain, an immediate-release analgesic can be prescribed in the first three days. After that time period, if further pain control is needed, it should be based on the PRN analgesic regimen of the past three days. ${ }^{36}$

In some instances, following acute pain treatment, longer-term pain care may be needed. The transdermal buprenorphine patch may be continued as appropriate or the clinician may want to rotate to another analgesic agent. Based on recent clinical trials, buprenorphine is 75 to 100 times more potent than morphine ${ }^{38,39}$ and a 1:75 buprenorphine transdermal patch-to-morphine equianalgesic ratio has been proposed but is not clinically confirmed. ${ }^{40}$ Even higher ratios of up to $1: 110$ or $1: 115$ have been stated in the literature. ${ }^{39}$ Thus, using the midpoint of these ratios ( 75 to 115 , that is, a 1:95 ratio), a seven-day transdermal buprenorphine patch of $5 \mu \mathrm{g} / \mathrm{h}$ is approximately equivalent to 9 to $14 \mathrm{mg}$ /day of morphine; $10 \mu \mathrm{g} / \mathrm{h}$ is equivalent to 18 to $28 \mathrm{mg} / \mathrm{day}$; and $20 \mu \mathrm{g} / \mathrm{h}$ would be 36 to $55 \mathrm{mg} /$ day. $^{36}$ Note that as with all equianalgesic strategies, caution, sound clinical judgment, and professional prudence should guide the dosing.

\section{Clinical Acceptance}

Transdermal buprenorphine is not widely prescribed, particularly for acute pain. The relatively low rates of prescription of transdermal buprenorphine may be due to the fact that clinicians may be unaware they can prescribe this product without an X-waiver or that the transdermal buprenorphine patch is indicated for pain control. Reasons for the under-utilization of transdermal buprenorphine patches are described in Table $1 .{ }^{37}$

\section{Discussion}

Many surgical procedures, such as hip or knee arthroplasty, involve moderate to severe pain over the course of several days following surgery. Such pain can delay ambulation and impede effective rehabilitation strategies. The role of a transdermal opioid patch in this setting may be appropriate as it provides effective analgesic, allows for good compliance, and offers certain advantages over other opioid analgesics, such as a ceiling effect for respiratory depression and less "likeability" as a drug of abuse. ${ }^{14,15}$ Although transdermal buprenorphine is a long-acting
Table I There are Multiple Reasons Why the Transdermal Buprenorphine System May Be Underutilized for Pain Control

\begin{tabular}{|c|c|}
\hline $\begin{array}{l}\text { Reason for Not Prescribing } \\
\text { Transdermal Buprenorphine } \\
\text { for Pain in Otherwise } \\
\text { Appropriate Patients }\end{array}$ & Response, Comments \\
\hline $\begin{array}{l}\text { Physician is not comfortable } \\
\text { prescribing opioids in general }\end{array}$ & $\begin{array}{l}\text { Pain relief sometimes requires } \\
\text { opioid analgesics; prescribers } \\
\text { who are not comfortable with } \\
\text { opioid prescribing should refer } \\
\text { the patient to a pain specialist }\end{array}$ \\
\hline $\begin{array}{l}\text { Physician is not comfortable } \\
\text { prescribing transdermal } \\
\text { buprenorphine }\end{array}$ & $\begin{array}{l}\text { No } X \text {-waiver is required; it is } \\
\text { indicated for pain; it has low } \\
\text { rates of abuse; the patch assures } \\
\text { good patient compliance }\end{array}$ \\
\hline $\begin{array}{l}\text { Physician is not aware that } \\
\text { buprenorphine is appropriate for } \\
\text { pain control; it's for opioid } \\
\text { maintenance }\end{array}$ & $\begin{array}{l}\text { The transdermal buprenorphine } \\
\text { patch is indicated for pain } \\
\text { control }\end{array}$ \\
\hline $\begin{array}{l}\text { Prescribing buprenorphine } \\
\text { patches will bring regulatory or } \\
\text { legal scrutiny on the hospital or } \\
\text { clinic }\end{array}$ & $\begin{array}{l}\text { The judicious and prudent } \\
\text { prescribing of opioid analgesics is } \\
\text { likely within the scope of sound } \\
\text { routine practice; buprenorphine } \\
\text { and in particular transdermal } \\
\text { buprenorphine has a reduced } \\
\text { potential for misuse as it is not } \\
\text { well liked by recreational users } \\
\text { and the patch makes it difficult to } \\
\text { extract the opioid agent }\end{array}$ \\
\hline $\begin{array}{l}\text { Insurance does not reimburse } \\
\text { for transdermal buprenorphine }\end{array}$ & $\begin{array}{l}\text { This varies by region and case; } \\
\text { contact your provider. In many } \\
\text { cases, transdermal } \\
\text { buprenorphine is a good and } \\
\text { defensible choice for analgesia }\end{array}$ \\
\hline It is difficult to dose the patch & $\begin{array}{l}\text { Patches come in multiple sizes } \\
\text { and can be cut to reduce dose or } \\
\text { more than one patch can be used } \\
\text { for higher doses }\end{array}$ \\
\hline $\begin{array}{l}\text { Since transdermal } \\
\text { buprenorphine is not indicated } \\
\text { for acute pain, it is better not to } \\
\text { use it }\end{array}$ & $\begin{array}{l}\text { The transdermal buprenorphine } \\
\text { system is safe and effective for } \\
\text { appropriate chronic pain patients } \\
\text { and its use for acute pain, } \\
\text { although not specifically } \\
\text { indicated, is reasonable and in } \\
\text { some cases may be an optimal } \\
\text { choice }\end{array}$ \\
\hline
\end{tabular}

opioid, it may be appropriate for acute pain of several days' duration. However, for acute pain or postsurgical pain likely to be of short duration, such as dental pain, it 
is not useful, because the patch lasts for seven days and has a slow onset of action.

Postsurgical pain control is an important aspect of clinical care and postsurgical pain is often undertreated. ${ }^{41}$ Inadequately treated postsurgical pain not only causes unnecessary suffering, it can delay ambulation, interfere with rehabilitation efforts, extend hospital stays, increase costs, decrease patient satisfaction, lead to complications, and has the potential to deteriorate into chronic pain syndromes, which are very challenging to manage effectively. ${ }^{42}$ In fact, chronic pain can be life altering for the patients and is associated with disability, depression, social isolation, and disruption in work, home, and family life. ${ }^{43}$

It appears that a major obstacle toward wider acceptance or at least consideration of transdermal buprenorphine as an analgesic agent for acute pain is the fact that buprenorphine is one of the two main agents used in opioid rehabilitation. As such, healthcare professionals may have "typecast" buprenorphine as solely an agent for opioid rehabilitation requiring specific prescribing credentials may be required (special training, $\mathrm{X}$-waiver). Transdermal buprenorphine has been approved for use in treating chronic pain $\left(\right.$ Butrans $^{\circledR}$, Purdue Pharma, LP, Stamford, Connecticut, United States of America). A parenteral form of buprenorphine has also been approved for use in chronic pain patients (Buprenex ${ }^{\circledR}$, Reckitt Benckiser Healthcare UK, Ltd, Hull, England). The transdermal buprenorphine product is not indicated for use in opioid rehabilitation. The variety of opioid products and formulations are summarized in Table 2.

A conundrum in clinical practice can occur when acute pain is to be treated in a patient already on buprenorphine maintenance. Buprenorphine has a long half-life and when rapid-onset acute pain relief is needed, it had been thought that buprenorphine might blunt the effects of short-acting opioids for acute pain. ${ }^{44,45}$ In other words, buprenorphine might occupy all or nearly all of the $\mu$ opioid receptors and not allow for pain relief. The 2004 guidelines from the Department of Health and Human Service Center for Substance Abuse Treatment has recommended that such patients discontinue buprenorphine maintenance and take short-acting opioids prescribed instead manage the acute pain. ${ }^{46}$ Recent literature has challenged this position and suggests it may be more effective to continue buprenorphine maintenance and concurrently administer short-acting analgesics (nonopioid or opioid, as appropriate) to treat pain. ${ }^{47}$ It has been argued that there is insufficient clinical
Table 2 Commercial Names and Indications for Buprenorphine Products

\begin{tabular}{|c|c|c|c|}
\hline $\begin{array}{l}\text { Commercial } \\
\text { Name }\end{array}$ & Manufacturer & Description & Use \\
\hline Belbuca & $\begin{array}{l}\text { BioDelivery } \\
\text { Sciences } \\
\text { International }\end{array}$ & Buccal film & Pain control \\
\hline Buprenex & $\begin{array}{l}\text { Reckitt } \\
\text { Benckiser }\end{array}$ & Injectable & Pain control \\
\hline Butrans & Teva & $\begin{array}{l}\text { Transdermal } \\
\text { system }\end{array}$ & Pain control \\
\hline Sublocade & Indivior & Injectable & $\begin{array}{l}\text { Opioid } \\
\text { maintenance }\end{array}$ \\
\hline $\begin{array}{l}\text { Suboxone SL } \\
\text { Film }\end{array}$ & \multirow[t]{3}{*}{$\begin{array}{l}\text { Reckitt } \\
\text { Benckiser }\end{array}$} & Buccal film & $\begin{array}{l}\text { Opioid } \\
\text { maintenance }\end{array}$ \\
\hline $\begin{array}{l}\text { Suboxone SL } \\
\text { Tablet }\end{array}$ & & $\begin{array}{l}\text { Oral } \\
\text { buprenorphine/ } \\
\text { naloxone }\end{array}$ & $\begin{array}{l}\text { Opioid } \\
\text { maintenance }\end{array}$ \\
\hline Subutex & & $\begin{array}{l}\text { Sublingual } \\
\text { tablet }\end{array}$ & $\begin{array}{l}\text { Opioid } \\
\text { maintenance }\end{array}$ \\
\hline Transtec & Grünenthal & $\begin{array}{l}\text { Transdermal } \\
\text { system }\end{array}$ & $\begin{array}{l}\text { Pain } \\
\text { (Europe) }\end{array}$ \\
\hline Zubsolv & Orexo & $\begin{array}{l}\text { Sublingual } \\
\text { tablet }\end{array}$ & $\begin{array}{l}\text { Opioid } \\
\text { maintenance }\end{array}$ \\
\hline
\end{tabular}

Note: Product names may be trademarks or registered trademarks of their respective owners.

evidence to support the discontinuation of buprenorphine maintenance while treating acute pain, although it may be appropriate in certain specific cases. ${ }^{47}$ Care must be taken if buprenorphine maintenance is discontinued that it can be promptly restarted without treatment gaps that may cause the patient to experience withdrawal symptoms. Since buprenorphine for opioid maintenance can only be prescribed in the United States to outpatient by those with waiver training and an $\mathrm{X}$ number, it may be that the patient experiences a time lag between the time temporary short-acting analgesics are discontinued and buprenorphine maintenance can resume. For optimal patient care and comfort, this transition must occur without any delays. A case report in the literature describes a surgical patient whose buprenorphine maintenance was discontinued but his primary care physician was not consulted, so the patient was unable to get buprenorphine maintenance upon release (the hospital could not prescribe it) and had to wait several days while he tried to 
contact his primary care physician. The patient relapsed with opioid use disorder before he could get his buprenorphine therapy restarted. ${ }^{48}$ Thus, if buprenorphine maintenance is discontinued for any reason, a restart plan must be in place to assure a smooth and rapid transition for the patient. A buprenorphine restart plan means that patients should be informed about how their buprenorphine maintenance will restart, and the clinical team associated with the surgery should consult with the rehabilitation clinical team.

This narrative review has several limitations. The studies on which this narrative review was based were few in number, relatively small, and involved patient populations with different conditions who may not be comparable to each other. Thus, it is not possible to analyze these data in any systematic statistical way, but it is possible to present the studies in narrative fashion. Larger controlled trials are needed.

\section{Conclusion}

Transdermal buprenorphine may be an appropriate analgesic product for short-term use for acute pain, particularly in the postoperative setting where pain may last several days. In general, transdermal buprenorphine is not frequently prescribed, likely because the drug is more associated with opioid rehabilitation than pain management. Nevertheless, the buprenorphine patch offers certain advantages for certain types of acute pain in appropriate patients.

\section{Funding}

No grant or funding supported this work.

\section{Disclosure}

Dr. Joseph V Pergolizzi Jr has previously been a speaker or consultant for Grünenthal, Purdue Pharma, and Insys but received no funding for the production of this invited manuscript. Dr Pergolizzi Jr reports personal fees from BDSI, during the conduct of the study. He also reports grants and/ or personal fees from Scilex, Salix, Regeneron, Teva, Pfizer, Lilly, Neumentum, and Neurana, outside the submitted work. The authors report no other conflicts of interest in this work.

\section{References}

1. Pergolizzi JV Jr, Mercadante S, Echaburu AV, et al. The role of transdermal buprenorphine in the treatment of cancer pain: an expert panel consensus. Curr Med Res Opin. 2009;25(6):1517-1528. doi: $10.1185 / 03007990902920731$
2. Hans G, Robert D. Transdermal buprenorphine - a critical appraisal of its role in pain management. J Pain Res. 2009;2:117-134. doi:10.2147/JPR.S6503

3. International Association for the Study of Pain. IASP terminology. International association for the study of pain. Education web site; 2020. Available from: https://www.iasp-pain.org/Education/Content. aspx?ItemNumber=1698. Accessed September 10, 2020.

4. Khanna IK, Pillarisetti S. Buprenorphine - an attractive opioid with underutilized potential in treatment of chronic pain. $J$ Pain Res. 2015;8:859-870. doi:10.2147/JPR.S85951

5. Davis MP, Pasternak G, Behm B. Treating chronic pain: an overview of clinical studies centered on the buprenorphine option. Drugs. 2018;78(12):1211-1228. doi:10.1007/s40265-018-0953-Z

6. Ahmadi J, Jahromi MS, Ehsaei Z. The effectiveness of different singly administered high doses of buprenorphine in reducing suicidal ideation in acutely depressed people with co-morbid opiate dependence: a randomized, double-blind, clinical trial. Trials. 2018;19 (1):462. doi:10.1186/s13063-018-2843-9

7. Stein C, Machelska H, Sharp BM. Modulation of peripheral sensory neurons by the immune system: implications for pain therapy. Pharmacol Rev. 2011;63(4):860-881. doi:10.1124/pr.110. 003145

8. Likar R. Transdermal buprenorphine in the management of persistent pain - safety aspects. Ther Clin Risk Manag. 2006;2(1):115-125.

9. Pergolizzi JV Jr, Raffa RB. Safety and efficacy of the unique opioid buprenorphine for the treatment of chronic pain. J Pain Res. 2019;12:3299-3317. doi:10.2147/JPR.S231948

10. Varrassi G, Marinangeli F, Ciccozzi A, Iovinelli G, Facchetti G, Ciccone A. Intra-articular buprenorphine after knee arthroscopy. A randomised, prospective, double-blind study. Acta Anaesthesiol Scand. 1999;43(1):51-55. doi:10.1034/j.1399-6576.1999.430112.x

11. Marinangeli F, Guetti C, Angeletti C, et al. Intravenous naloxone plus transdermal buprenorphine in cancer pain associated with intractable cholestatic pruritus. J Pain Symptom Manage. 2009;38(4):e5-8. doi:10.1016/j.jpainsymman.2009.05.008

12. Guetti C, Angeletti C, Marinangeli F, et al. Transdermal buprenorphine for central neuropathic pain: clinical reports. Pain Pract. 2011;11(5):446-452. doi:10.1111/j.1533-2500.2010.00434.x

13. DEA. Drug scheduling. Drug Enforcement Administration; 2019. Available from: https://www.dea.gov/drug-scheduling. Accessed August 28, 2019.

14. Pergolizzi J, Aloisi AM, Dahan A, et al. Current knowledge of buprenorphine and its unique pharmacological profile. Pain Pract. 2010;10(5):428-450. doi:10.1111/j.1533-2500.2010.00378.x

15. Davis MP. Twelve reasons for considering buprenorphine as a frontline analgesic in the management of pain. $J$ Support Oncol. 2012;10(6):209-219.

16. Pergolizzi JV Jr, Scholten W, Smith KJ, Leighton-Scott J, Willis JC, Henningfield JE. The unique role of transdermal buprenorphine in the global chronic pain epidemic. Acta Anaesthesiol Taiwan. 2015;53 (2):71-76. doi:10.1016/j.aat.2015.06.001

17. Desai SN, Badiger SV, Tokur SB, Naik PA. Safety and efficacy of transdermal buprenorphine versus oral tramadol for the treatment of post-operative pain following surgery for fracture neck of femur: a prospective, randomised clinical study. Indian J Anaesth. 2017;61 (3):225-229. doi:10.4103/ija.IJA_208_16

18. Basurto Ona X, Rigau Comas D, Urrútia G. Opioids for acute pancreatitis pain. Cochrane Database Syst Rev. 2013;(7):Cd009179.

19. Jakobs R, Adamek MU, von Bubnoff AC, Riemann JF. Buprenorphine or procaine for pain relief in acute pancreatitis. A prospective randomized study. Scand J Gastroenterol. 2000;35 (12):1319-1323. doi:10.1080/003655200453692

20. Niyogi S, Bhunia P, Nayak J, Santra S, Acharjee A, Chakraborty I. Efficacy of transdermal buprenorphine patch on post-operative pain relief after elective spinal instrumentation surgery. Indian J Anaesth. 2017;61(11):923-929. doi:10.4103/ija.IJA_118_17 
21. Machado FC, Neto GC, Paiva LO, et al. [Transdermal buprenorphine for acute postoperative pain: a systematic review]. Rev Bras Anestesiol. 2020;70(4):419-428. doi:10.1016/j.bjan.2020.04. 004.Portuguese.

22. Setti T, Sanfilippo F, Leykin Y. Transdermal buprenorphine for postoperative pain control in gynecological surgery: a prospective randomized study. Curr Med Res Opin. 2012;28(10):1597-1608. doi:10.1185/03007995.2012.719864

23. Rivera-Ruiz A, Villegas-Gomez R, Mejia-Terrazas G. Transdermal buprenorphine in postoperative pain. Controlled clinical trial. Rev Mex Anest. 2018;41(2):83-87.

24. Xu X, Xie L, Liu H, Hu Y. Transdermal buprenorphine patch versus oral celecoxib for pain management after total knee arthroplasty: an open- label, randomized controlled trial. Orthop Traumatol Surg Res 2020;106(5):915-919. doi:10.1016/j.otsr.2020.04.010

25. Yadav M, Mohan CL, Srikanth I, Raj ER, Gopinath R, Chandrasekhar P. Effect of preoperative application of buprenorphine transdermal patch on analgesic requirement in postoperative period in hip and knee replacement surgeries. J Anaesthesiol Clin Pharmacol. 2019;35(1):124-128. doi:10.4103/joacp.JOACP_13_17

26. Privitera C, Guzzetta G. 809. Postoperative pain management in shoulder surgery with transdermal (TDS) buprenorphine patches. Reg Anesth Pain Med. 2008;33(Suppl 1):e184-e184.

27. Kim HJ, Ahn HS, Nam Y, Chang BS, Lee CK, Yeom JS. Comparative study of the efficacy of transdermal buprenorphine patches and prolonged-release tramadol tablets for postoperative pain control after spinal fusion surgery: a prospective, randomized controlled non-inferiority trial. Eur Spine J. 2017;26(11):2961-2968. doi:10.1007/s00586-017-5213-5

28. Privitera C, Guzzetta G. Transdermal (TDS) buprenorphine patches for postoperative pain management in orthopaedic surgery in the elderly. Reg Anesth Pain Med. 2008;33:e187.

29. Londhe S, Patwardhan M, Shah R, Oak M. Efficacy and safety of buprenorphine transdermal patch for immediate postoperative analgesia after total knee arthroplasty surgery. J Arthroplasty. 2020;35(6, Supplement):S178-S181. doi:10.1016/j.arth.2020.02.015

30. Luo P, Lou J, Yang S. Pain management during rehabilitation after distal radius fracture stabilized with volar locking plate: a prospective cohort study. Biomed Res Int. 2018;2018:5786089. doi:10.1155/2018/ 5786089

31. Dahan A, Yassen A, Bijl H, et al. Comparison of the respiratory effects of intravenous buprenorphine and fentanyl in humans and rats. Br J Anaesth. 2005;94(6):825-834. doi:10.1093/bja/aei145

32. Dahan A, Yassen A, Romberg R, et al. Buprenorphine induces ceiling in respiratory depression but not in analgesia. Br J Anaesth. 2006;96 (5):627-632. doi:10.1093/bja/ael051

33. Vander Hulst K, Parera Amer E, Jacobs C, et al. Allergic contact dermatitis from transdermal buprenorphine. Contact Dermatitis. 2008;59(6):366-369. doi:10.1111/j.1600-0536.2008.01472.x

34. Harris SC, Morganroth J, Ripa SR, Thorn MD, Colucci S. Effects of buprenorphine on QT intervals in healthy subjects: results of 2 randomized positive- and placebo-controlled trials. Postgrad Med. 2017;129(1):69-80. doi:10.1080/00325481.2017. 1270156

Journal of Pain Research

\section{Publish your work in this journal}

The Journal of Pain Research is an international, peer reviewed, open access, online journal that welcomes laboratory and clinical findings in the fields of pain research and the prevention and management of pain Original research, reviews, symposium reports, hypothesis formation and commentaries are all considered for publication. The manuscript

Submit your manuscript here: https://www.dovepress.com/journal-of-pain-research-journal
35. Tran PN, Sheng J, Randolph AL, et al. Mechanisms of QT prolongation by buprenorphine cannot be explained by direct hERG channel block. PLoS One. 2020;15(11):e0241362. doi:10.1371/journal.pone. 0241362

36. VA Pharmacy Benefits Management Services MAP. Buprenorphine transdermal delivery system (BUTRANS), C-III.. Veterans Administration; 2015. Available from: https://www.pbm.va.gov/PBM/ clinicalguidance/drugmonographs/Buprenorphine_Transdermal_ System_BUTRANS_Monograph.pdf. Accessed December 8, 2020.

37. Wiegand TJ, Le Lait M-C, Bartelson BB, Dart RC, Green JL. Analysis of the abuse and diversion of the buprenorphine transdermal delivery system. J Pain. 2016;17(6):745-752. doi:10.1016/j.jpain.2016.02.015

38. Sittl R, Nuijten M, Nautrup BP. Changes in the prescribed daily doses of transdermal fentanyl and transdermal buprenorphine during treatment of patients with cancer and noncancer pain in Germany: results of a retrospective cohort study. Clin Ther. 2005;27(7):1022-1031. doi:10.1016/j.clinthera.2005.06.024

39. Sittl R, Likar R, Nautrup BP. Equipotent doses of transdermal fentanyl and transdermal buprenorphine in patients with cancer and noncancer pain: results of a retrospective cohort study. Clin Ther. 2005;27(2):225-237. doi:10.1016/j.clinthera.2005.02.012

40. Mercadante S, Caraceni A. Conversion ratios for opioid switching in the treatment of cancer pain: a systematic review. Palliat Med. 2011;25(5):504-515. doi:10.1177/0269216311406577

41. Gan TJ. Poorly controlled postoperative pain: prevalence, consequences, and prevention. J Pain Res. 2017;10:2287-2298. doi:10. 2147/JPR.S144066

42. Garimella V, Cellini C. Postoperative pain control. Clin Colon Rectal Surg. 2013;26(3):191-196. doi:10.1055/s-0033-1351138

43. Dueñas M, Ojeda B, Salazar A, Mico JA, Failde I. A review of chronic pain impact on patients, their social environment and the health care system. J Pain Res. 2016;9:457-467. doi:10.2147/JPR. $\mathrm{S} 105892$

44. Greenwald MK, Comer SD, Fiellin DA. Buprenorphine maintenance and mu-opioid receptor availability in the treatment of opioid use disorder: implications for clinical use and policy. Drug Alcohol Depend. 2014;144:1-11. doi:10.1016/j.drugalcdep.2014.07.035

45. Greenwald MK, Johanson C-E, Moody DE, et al. Effects of buprenorphine maintenance dose on $\mu$-opioid receptor availability, plasma concentrations, and antagonist blockade in heroin-dependent volunteers. Neuropsychopharmacology. 2003;28(11):2000-2009. doi:10.10 38/sj.npp. 1300251

46. Center for Substance Abuse T. SAMHSA/CSAT treatment improvement protocols. In: Clinical Guidelines for the Use of Buprenorphine in the Treatment of Opioid Addiction. Rockville (MD): Substance Abuse and Mental Health Services Administration (US); 2004.

47. Haber L, DeFries T, Martin M. Things we do for no reason: discontinuing buprenorphine when treating acute pain. J Hosp Med. 2019;10(10):633-635. doi:10.12788/jhm.3265

48. Cooper R, Vanjani R, Trimbur MC. Acute pain management in patients treated with buprenorphine: a teachable moment. JAMA Intern Med. 2019;179(10):1415-1416. doi:10.1001/jamainternmed. 2019.3103

management system is completely online and includes a very quick and fair peer-review system, which is all easy to use. Visit http:// www.dovepress.com/testimonials.php to read real quotes from published authors. 